\title{
Transcriptional profiling reveals intrinsic mRNA alterations in multipotent mesenchymal stromal cells isolated from bone marrow of newly-diagnosed type 1 diabetes patients
}

Kalil A. de Lima ${ }^{1,2,6^{*}}$, Gislane L. V. de Oliveira ${ }^{1,2}$, Juliana N. U. Yaochite ${ }^{1,2,3}$, Daniel G. Pinheiro', Júlia T. C. de Azevedo ${ }^{1,2}$, Wilson Araujo Silva Jr ${ }^{1}$, Dimas T. Covas ${ }^{1,4}$, Carlos E. B. Couri ${ }^{1,4}$, Belinda P. Simões ${ }^{1,4}$, Julio C. Voltarelli ${ }^{1,4}$, Maria C. Oliveira ${ }^{1,4+}$ and Kelen C. R. Malmegrim ${ }^{1,5+}$

\begin{abstract}
Background: Bone marrow multipotent mesenchymal stromal cells (MSCs) are a diverse subset of precursors that contribute to the homeostasis of the hematopoietic niche. MSCs can be isolated and expanded in vitro and have unique immunomodulatory and regenerative properties that make them attractive for the treatment of autoimmune diseases, including type 1 diabetes (T1D). Whether autologous or allogeneic MSCs are more suitable for therapeutic purposes has not yet been established. While autologous MSCs may present abnormal function, allogeneic cells may be recognized and rejected by the host immune system. Thus, studies that investigate biological characteristics of MSCs isolated from T1D patients are essential to guide future clinical applications.

Methods: Bone marrow-derived MSCs from recently diagnosed type 1 diabetes patients (T1D-MSCs) were compared with those from healthy individuals (C-MSCs) for morphological and immunophenotypic characteristics and for differentiation potential. Bioinformatics approaches allowed us to match absolute and differential gene expression of several adhesion molecules, immune mediators, growth factors, and their receptors involved with hematopoietic support and immunomodulatory properties of MSCs. Finally, the differentially expressed genes were collated for functional pathway enrichment analysis.
\end{abstract}

Results: T1D-MSCs and C-MSCs were similar for morphology, immunophenotype, and differentiation potential. Our absolute gene expression results supported previous literature reports, while also detecting new potential molecules related to bone marrow-derived MSC functions. T1D-MSCs showed intrinsic abnormalities in mRNA expression, including the immunomodulatory molecules VCAM-1, CXCL12, HGF, and CCL2. Pathway analyses revealed activation of sympathetic nervous system and JAK STAT signaling in T1D-MSCs.

\footnotetext{
* Correspondence: kalil.lima@usp.br

Julio C. Voltarelli died before publication of this work was completed.

${ }^{\dagger}$ Equal contributors

${ }^{1}$ Center for Cell-Based Research, Regional Blood Center of Ribeirao Preto,

Ribeirao Preto Medical, University of Sao Paulo, Ribeirao Preto, Brazil

${ }^{2}$ Department of Biochemistry and Immunology, Ribeirao Preto Medical

School, University of Sao Paulo, Ribeirao Preto, Brazil

Full list of author information is available at the end of the article
} 
(Continued from previous page)

Conclusions: Collectively, our results indicate that MSCs isolated from T1D patients present intrinsic transcriptional alterations that may affect their therapeutic potential. However, the implications of these abnormalities in T1D development as well as in the therapeutic efficacy of autologous MSCs require further investigation.

Keywords: Mesenchymal stromal cells, Bone marrow, Type 1 diabetes, Transcriptome, Microarrays, Cell therapy

\section{Background}

Multipotent mesenchymal stromal cells (MSCs) are a diverse subset of precursors found in the stromal fraction of the bone marrow and other adult tissues, presenting osteogenic, adipogenic, and chondrogenic differentiating potentials [1-3]. Stromal cells are usually detected in perivascular areas and present immunomodulatory properties $[1,4]$. They have therefore been explored as tools to modulate inflammatory response, induce peripheral tolerance, and promote tissue repair [5]. In addition, murine bone marrow MSCs are physically close to most hematopoietic stem cells (HSCs) and express high levels of genes related to HSC maintenance and retention, which makes them important contributors for maturation of the hematopoietic compartment [6-9].

MSCs can be expanded in vitro and have unique immunomodulatory and regenerative properties, which render them attractive for treatment of autoimmune and inflammatory disorders [10]. Initial studies revealed that bone marrow MSCs inhibited T-cell proliferation in vitro and were immunosuppressive in a model of skin allograft rejection [11-13]. In addition, bone marrow MSCs were shown to inhibit dendritic cell differentiation and B-cell proliferation, impair the cytolytic potential of natural killer cells, and increase $\mathrm{T}$ regulatory cell (Treg) differentiation and function [10, 14]. The therapeutic effects of MSCs are partially due to their ability to produce and secrete a vast array of soluble mediators and other molecules with immunomodulatory properties, such as hepatocyte growth factor (HGF), indoleamine 2,3-dioxygenase (IDO), cyclooxygenase-2 (COX2), IL-10, prostaglandin E2, nitric oxide, and transforming growth factor beta 1 (TGF $\beta-1)$ [14].

In the last decade, many studies have demonstrated the therapeutic potential of MSC transplantation in experimental models of autoimmune diseases, including type 1 diabetes (T1D) [15-18]. In 2006, Lee et al. [19] showed that human MSCs were able to migrate and promote pancreatic repair in nonobese diabetic/severe combined immunodeficiency (NOD/SCID) mice. Later, several other studies in experimental models of T1D have demonstrated that MSC transplantation delays the onset of disease or even reverses hyperglycemia [18-21]. Further investigations have shown modulation of the inflammatory response and expansion of Tregs, in consequence decreasing pancreatic infiltrates and improving endogenous insulin production [20-23]. Transdifferentiation is not considered a major therapeutic mechanism of MSCs in T1D. Instead, cytokine and soluble factor release may account for immunosuppressive, antiinflammatory, and regenerative properties that abrogate the autoimmune response and stimulate the survival and proliferation of resident/progenitor pancreatic cells through paracrine pathways [24].

In-vitro expanded MSCs are able to escape the immune system when administered intravenously, and may be useful tools in the allogeneic transplantation setting [25]. Under resting conditions, MSCs express low levels of major histocompatibility complex (MHC) class I, and do not express MHC class II or co-stimulatory molecules, such as CD80, CD86, CD40, or CD40L [26, 27]. The modulatory activity of MSCs depends on a process of "licensing" promoted by proinflammatory cytokines, especially tumor necrosis factor (TNF) and interferon gamma (IFN- $\gamma$ ) [28-34]. In a murine model, MSCs treated with high IFN- $\gamma$ levels before infusion became immediately activated and were able to suppress graft versus host disease (GvHD) more efficiently than a fivefold-greater number of MSCs that had not been pretreated [35]. Conversely, under low IFN- $\gamma$ levels MSCs upregulate the expression of MHC class II, behave as antigen-presenting cells, and, in consequence, may be recognized by alloreactive cells after transplantation [36-40]. Accordingly, whether allogeneic MSCs persist in the tissues of immunocompetent hosts after transplantation still remains under debate [41].

In the field of human autoimmune diseases, results are frequently divergent and lack consistency. In patients with Crohn's disease (CD) [42], rheumatoid arthritis (RA) [43], systemic sclerosis (SSc) [44], and multiple sclerosis (MS) [45], MSCs were shown similar to those from healthy controls. In other studies, however, abnormalities were described in MSCs isolated from patients with SSc [46, 47], systemic lupus erythematosus (SLE) [48, 49], MS [50], and psoriasis [51-54]. While the clinical relevance of such findings has not yet been established, currently there is weak support for either autologous or allogeneic MSC-based therapies.

In-vivo studies are also somewhat contradictory. In T1D patients, a small clinical trial showed modest but significant preservation of C-peptide levels after transplantation with autologous MSCs [55]. Accordingly, in 
animal models, murine MSCs from both healthy and diabetic animals were therapeutically effective [56, 57]. On the other hand, when murine bone marrow-derived MSCs were used to treat prediabetic NOD mice, onset of disease was delayed by MSCs isolated from BALB/c, but not by autologous MSCs [55]. These data indicate that available evidence is still not strong enough to support a recommendation and that more studies should be performed in order to fully establish advantages and weaknesses of autologous or allogeneic MSCs.

Further studies to investigate the genetic and biological profiles of MSCs isolated from patients with autoimmune diseases are still warranted. To the best of our knowledge, it remains unknown whether MSCs isolated from newly diagnosed T1D patients have a similar molecular profile compared with their healthy counterparts. For this purpose, we characterized the global gene expression of bone marrow MSCs isolated from healthy individuals (controls, C-MSCs) and newly diagnosed T1D patients (T1D-MSCs). Herein, we describe the absolute and differential gene expression of several molecules involved with immunomodulation and hematopoietic support in C-MSCs and T1D-MSCs.

\section{Methods}

\section{Patients and controls}

Twenty-one T1D patients of median age 16 (range 13$31)$ years, $71 \%(n=15)$ male, were enrolled in this study, having been diagnosed with T1D within the previous 6 weeks. All patients had positive serum levels of antiglutamic acid decarboxylase (anti-GAD) antibodies, and did not report any previous episodes of diabetic ketoacidosis (Additional file 1: Table S1). The control group included 10 healthy subjects, $50 \%$ male $(n=5)$, with median age 34 (range 19-48) years, who had already been enrolled as bone marrow donors for allogeneic transplantation, and who voluntarily agreed to donate an additional $5 \mathrm{ml}$ of bone marrow aspirate for research. All procedures were approved by the Institutional Review Board (Research Ethical Committee of Clinical Hospital of Ribeirao Preto Medical School, CEP-HCRPUSP \#10095/02) and written informed consent was obtained from all individuals before bone marrow aspiration. Bone marrow samples were obtained from T1D patients and healthy donors through needle aspiration of the iliac crest.

\section{Isolation and culture of bone marrow MSCs}

Bone marrow aspirates were collected in the presence of EDTA, and mononuclear cells were separated by FicollHypaque (Amersham-Pharmacia, Uppsala, Sweden) gradient density separation. Subsequently, the mononuclear cell layer was harvested and washed twice in PBS. Cells were centrifuged and resuspended in alpha-Minimum
Essential Medium ( $\alpha$-MEM; Gibco, Life Technologies, Grand Island, NY, USA) medium supplemented with $15 \%$ fetal bovine serum (FBS; Thermo Scientific, Rockford, IL, USA), $100 \mu \mathrm{g} / \mathrm{ml}$ penicillin, $100 \mu \mathrm{g} / \mathrm{ml}$ streptomycin, and 2 mML-glutamine (all from Gibco, Life Technologies). The cells were then seeded in $75 \mathrm{~cm}^{2}$ flasks and incubated at $37{ }^{\circ} \mathrm{C}$ in a humidified atmosphere containing $5 \% \mathrm{CO}_{2}$ (passage 0). After $24 \mathrm{~h}$, nonadherent cells were removed by replacing the medium, and fresh medium was added. The culture was examined daily by phase-contrast microscopy and every 3 days the medium was partially changed to remove nonadherent cells and cell debris. When the cells reached at least $70-80 \%$ confluence, they were detached using trypsin-EDTA $0.05 \%$ (Gibco, Life Technologies) and passaged at a split ratio of 1:2 until the third or fourth passage.

\section{MSC morphology and immunophenotypic profiling}

After expansion in culture until the third or fourth passage, C-MSCs and T1D-MSCs were assessed for morphology by inverted (Axiovert $40 \mathrm{CFL}$; Carl Zeiss, Goetingen, Germany) and light (TS100; Nikon, China) microscopy. C-MSCs and T1D-MSCs were then incubated with monoclonal antibodies against CD45, CD14, CD44, CD29, CD51/61, CD13, CD54, HLA-CLASS I (HLA-A/B/C), HLA-CLASS II (HLA-DRB1), CD90, KDR, CD34, CD49e, CD105, CD73, or STRO-1 (BectonDickinson (BD), San Jose, CA, USA) for $30 \mathrm{~min}$ in the dark. Immunophenotypic analysis was performed using FACSCalibur (BD) equipment and 20,000 cells were acquired and analyzed by FlowJo 10 software.

\section{Differentiation into mesoderm lineages}

In-vitro adipogenic differentiation of C-MSCs and T1DMSCs was induced using $\alpha$-MEM medium supplemented with $15 \%$ FBS, 100 mM dexamethasone (Prodome, Campinas, SP, Brazil), $10 \mu \mathrm{g} / \mathrm{ml}$ insulin (Sigma-Aldrich, Saint Louis, MO, USA), and $100 \mu \mathrm{M}$ indomethacin (Sigma-Aldrich). MSCs cultured with $\alpha$-MEM medium supplemented with $15 \%$ FBS served as the negative control. Culture medium was changed every 3 days and cells were maintained in culture for 21 days. MSCs were then fixed with ethanol (70 \%) and stained with Sudan IIScarlate and Harris hematoxylin. The presence of lipid vacuoles in the MSCs was observed through light microscopy.

Osteoblastic differentiation was initiated by seeding MSCs in the presence of osteogenic differentiation medium composed of MSC growth medium; that is,

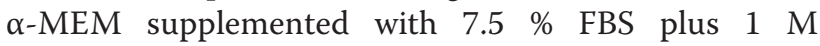
glycerol-2-phosphate (Sigma-Aldrich), $20 \mathrm{mML}$-ascorbic acid (Sigma-Aldrich), and $0.1 \mathrm{mM}$ dexamethasone (Sigma-Aldrich). The culture medium was replaced every 3 days during a period of 21 days. During the 
same period, control cells were kept in standard $\alpha$-MEM with 7.5 \% FBS (HyClone; Thermo Fisher Scientific Inc., USA).

All cells were fixed and stained by the von Kossa method, which indicates calcium deposition, subsequently analyzed with an Axioscope 2.0 Zeiss microscope equipped with an AxioCam HR camera (Carl Zeiss).

For chondrogenic induction, $10^{6}$ cell pellets were cultured for 3 weeks under chondrogenic medium containing $10 \mathrm{ng} / \mathrm{ml}$ of TGF- $\beta 3$ (PeproTech, USA), $100 \mu \mathrm{M}$ sodium pyruvate (Gibco, Carlsbad, CA, USA), $0.1 \mu \mathrm{M}$ dexamethasone (Decadron, Brazil), $50 \mu \mathrm{M}$ ascorbic acid, 0.5× ITS A (insulin-transferrin-selenium-sodium pyruvate A; Gibco), and $0.2 \%$ human albumin (Aventis Behring, Australia) PeproTech in DMEM (Gibco). Cell pellets were harvested at 3 weeks post induction, fixed overnight with $4 \%$ PFA, and sections were prepared for immunohistochemistry. For staining, sections were incubated with anti-type II collagen rabbit antibody (Novocastra ${ }^{\mathrm{Tx}}$, Newcastle, UK), and subsequently stained with hematoxylin and eosin and analyzed with an Axioscope 2.0 Zeiss microscope equipped with an AxioCam HR camera (Carl Zeiss).

\section{Microarray analysis}

Total RNA was isolated from random T1D-MSCs $(n=11)$ and C-MSCs $(n=10)$ by the Trizol method (Invitrogen, USA) and purified by RNeasy commercial kit (QIAGEN, USA) according to the manufacturers' recommendations. RNA integrity was evaluated by microfluidic electrophoresis using Agilent 6000 RNA Nano chips and an Agilent 2100 Bioanalyzer (Agilent Technologies, Santa Clara, CA, USA). Only RNA samples that were free of proteins and phenol and that featured an RNA Integrity Number $($ RIN $) \geq 9.0$ were used. Random RNA samples of T1DMSCs and C-MSCs were selected ( $n=4$ for each group) and the global gene expression was analyzed by the One-color Microarray-Based Gene Expression Analysis Protocol system (Agilent Technologies) on glass slides with four microarrays of 44,000 probes each $(4 \times 44 \mathrm{k})$. The preprocess and statistical microarray analyses were performed using algorithms available in the $\mathrm{R}$ platform ( $R$ Foundation, Vienna, Austria) through the Linear Models for Microarray Data (LIMMA) package [56]. Heatmaps were generated by the HeatMapViewer module of GenePattern 2.0 software [57]. Genes with $p<0.05$ and fold change $(\mathrm{FC})>2.0$ were considered differentially expressed. Microarray data were deposited in the public database ArrayExpress (http://www.ebi.ac.uk/ arrayexpress [ArrayExpress:E-MTAB-2976]).

\section{Absolute and differential expression of predefined gene categories}

Encoding genes for collagens, integrins, and laminins, as well as for cytokines, growth factors, and chemokines, and their respective receptors, were classified according to the binary relationships of biological entities (BRITE) category available in the Kyoto Encyclopedia of Genes and Genomes (KEGG) database [58]. Different categories were represented by heatmaps generated by the HeatMapViewer module of the GenePattern 2.0 software [57]. Genes with multiple probes were represented by the median value. For absolute gene expression representation, genes in each category were sorted in ascending order, according to average value expression of the control group. Highly expressed genes had absolute gene expression value $(E V)>120$. Only genes with $p<0.05$ and FC $>2.0$ were included in the heatmaps for differential gene expression.

\section{Functional enrichment analysis}

The functional enrichment analysis was performed using DAVID software (Database for Annotation, Visualization and Integrated Discovery; National Cancer Institute at Frederick, Frederick, MD, USA) [59, 60]. The differentially expressed official gene symbols (upregulated and downregulated) were imported to the program and the Functional Annotation Chart module was used. In this module, we performed a standard ontology (GO FAT) available for all categories of the Gene Ontology database (biological process, molecular function, and cellular component), as well as analysis of the KEGG pathways database. Categories and pathways with $p>0.05$ were considered statistically significant (Benjamini correction).

\section{Gene set enrichment analysis}

Gene set enrichment analysis (GSEA) was performed using the GSEA 2.07 software (Broad Institute from Massachusetts Institute of Technology, MIT, Cambridge, MA, USA). The differentially expressed probes $(p<0.05)$ were imported to the program, and gene ontology and KEGG pathway analyses were performed with 1000 permutations (gene set type) for $p$-value calculation. Default parameters were used, except for "collapsing mode for probe sets $=>1$ gene", in which the median value was used. Categories with nominal $p<0.05$ and false discovery rate $(\mathrm{FDR})<0.25$ were considered statistically significant.

\section{Functional pathway analysis}

To assess biological relationships among genes, the gene list with $p<0.05$ and $\mathrm{FC}>2.0$ were ascertained using the Ingenuity Pathway Analysis (IPA) software (Ingenuity System, Redwood City, CA, USA; http:// www.ingenuity.com), which assigns a $p$ value to each network, according to the degree of overrepresentation of input genes as compared with the Ingenuity Pathways Knowledge database. 


\section{Real-time PCR}

cDNA was synthesized from different RNA samples used for microarrays (T1D-MSCs, $n=7$ and C-MSCs, $n=6$ ) using 200 ng of total RNA (High-Capacity cDNA Reverse Transcription Kit; Life Technologies, USA). For microarray validation, real-time PCR was performed with the Taqman Gene Expression Assay (Applied Biosystems, USA) according to the manufacturer's protocol. Target gene expression was calculated using the comparative method for relative quantification after normalization to GAPDH gene expression: GAPDH, Hs02758991_g1; CXCL12, Hs03676656_mH; and VCAM1, Hs01003372_m1.

\section{In-vitro migration assay}

In-vitro migration was assayed by transwell chamber (BD, Franklin Lakes, NJ, USA) with $8 \mu \mathrm{m}$ porosity polyethylene terephthalate (PET) membrane. C-MSCs $(n=5)$ and T1D-MSCs $(n=5)$ were seeded in the upper layers of membranes with $100 \mu \mathrm{l}$ of $\alpha$-MEM medium without FBS. One chamber was inserted into each well of a 24-well plate filled with $600 \mu \mathrm{l}$ of $\alpha$-MEM supplemented with $50 \%$ FBS. MSCs were incubated for $6 \mathrm{~h}$ at $37{ }^{\circ} \mathrm{C}$. Cells that passed through the membrane pores to the underside were counterstained by Giemsa (Sigma-Aldrich). Nonmigrated cells were scraped off the upper surface of the membrane with a cotton swab. For each membrane, the number of migrated MSCs was counted in seven different fields using light microscopy.

\section{Results}

T1D-MSCs present typical morphology, immunophenotype, and mesodermic lineage differentiation

T1D-MSCs or C-MSCs were morphologically and immunophenotypically characterized in vitro. We did not observe differences between C-MSCs and T1DMSCs concerning proliferative capacity or doubling time (data not shown). In general, MSCs isolated from both groups achieved $70-80 \%$ confluence every 7 days. MSCs appeared as a typical monolayer of spindle-shaped fibroblast-like cells and demonstrated ability to adhere to plastic during in-vitro expansion. At the third passage, T1D-MSCs were morphologically similar to C-MSCs (Fig. 1a). No significant difference between T1D-MSCs and C-MSCs was observed in the expression of typical MSC markers. Both MSC populations were positive for CD90, CD13, CD29, CD105, CD49e, CD73, CD44, HLA-ABC, CD166, CD54, CD106, and STRO-1, and were negative for the hematopoietic/endothelial markers CD51/61, CD45, CD34, CD14, HLA-DR, and KDR (Fig. 1b, Additional file 2: Table S2). Furthermore, cultured T1D-MSCs and C-MSCs, under specific stimuli, were able to differentiate towards adipogenic, osteogenic, and chondrogenic lineages (Fig. 1c).

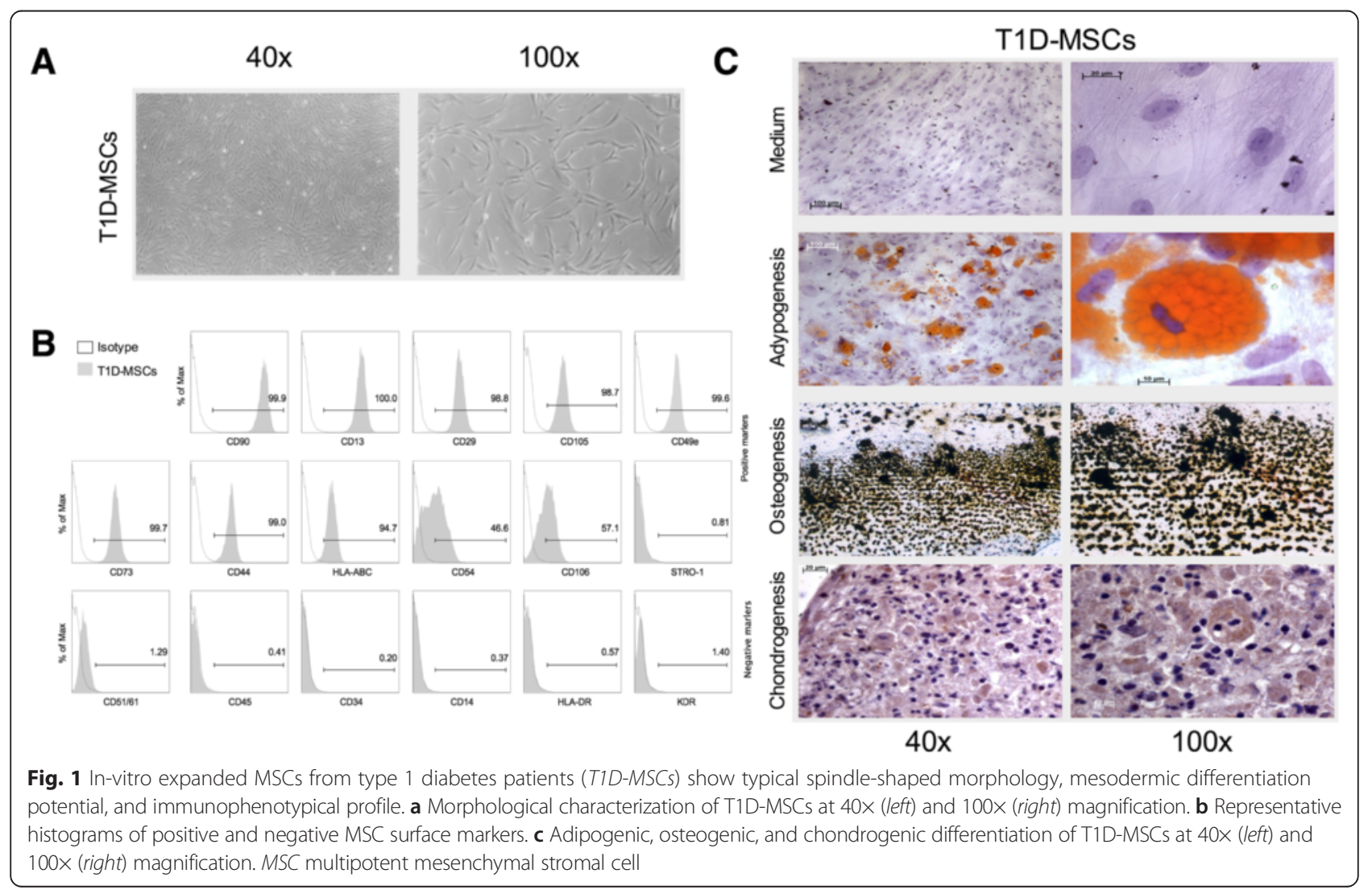


Transcriptional profile of T1D-MSCs is distinct from their healthy counterparts

To investigate whether T1D-MSCs present transcriptome abnormalities and to better understand molecular pathways that may regulate T1D-MSC biology, we performed a global gene expression analysis by microarray.

Unsupervised clustering analysis showed distinctive gene expression signatures comparing T1D-MSCs to C-MSCs (Additional file 3: Figure S1) and we observed differential expression of 2978 probes between the groups $(\mathrm{FC}>2, \mathrm{p}<0.05)$. Most of these probes were found upregulated in T1D-MSCs, when compared with C-MSCs (1926 upregulated and 1052 downregulated probes) (Fig. 2).

Aside from their role as structural elements, MSCs serve as resident sentinels that, upon activation, express surface molecules and produce soluble factors, coordinating tissue regeneration and inflammatory responses [4, 61]. In order to characterize the gene expression of several adhesion molecules, immune mediators, growth factors, and their receptors in bone marrow-derived MSCs from T1D patients and healthy controls, we first determined which mRNAs were more intensively expressed, using absolute gene expression analysis. Then, we specifically investigated which of these molecules were differentially expressed between T1D-MSCs and C-MSCs.
VCAM-1 and other adhesion-related molecules are differentially regulated in T1D-MSCs

Cultured MSCs from both groups (T1D-MSCs and CMSCs) presented increased absolute mRNA expression of collagens, integrins, laminins, and other molecules related to extracellular matrix (ECM) maintenance, cell-cell adhesion, and cell-ECM interaction (EV > 120). Genes encoding type I, IV, V, VI, and VIII collagens were overexpressed (Fig. 3a), as well as those for CD29 (ITGB1), CD51 (ITGAV), and CD49a (ITGA1) (Fig. 3b). A similar increase was observed for codification of the three types of laminin chains, especially the $\beta$ chain (Fig. 3c), and for other adhesion-related genes (absolute expression), such as VCAM1, THY1, and CD44 (Additional file 4: Figure S2).

Bioinformatics analysis was used to identify adhesionrelated genes that were differentially expressed between T1D-MSCs and C-MSCs (FC > 2.0, $p<0.05)$. VCAM1 was found downregulated in T1D-MSCs, and differences were also detected for expression of SEMA4A, ITGA7, ITGB1, and LAMA3 (Fig. 4a). Microarray analysis was validated by quantitative real-time PCR, confirming that VCAM1 was downregulated in T1D-MSCs (Fig. 4b).

\section{CXCL12, CCL2, and other chemotaxis-related molecules} are differentially regulated in T1D-MSCs

MSCs are able to migrate to sites of inflammation and to regulate the traffic of different hematopoietic cells.
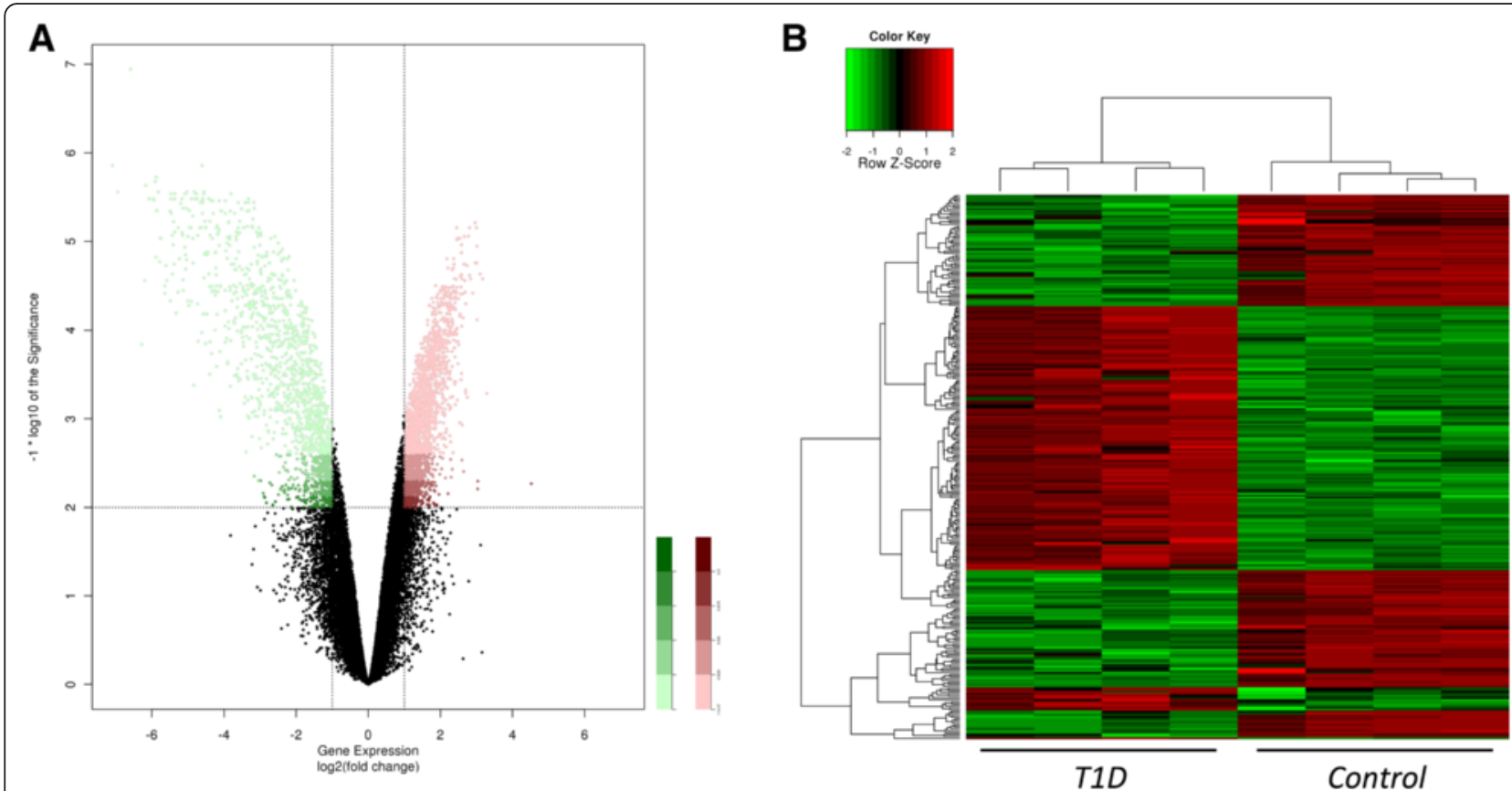

Fig. 2 Distinct global gene expression in T1D-MSCs and C-MSCs. A total of 2149 genes were differentially expressed between T1D-MSCs ( $n=4$ ) and C-MSCs $(n=4)$. T1D-MSCs showed 1515 upregulated genes and 634 downregulated genes (FC $>2, p<0.01$, Student $t$ test, Benjamini Hochberg correction). a Volcano plot of differentially expressed probes between T1D-MSCs and C-MSCs. Each plot represents one probe. Upregulated probes in T1D-MSCs are shown in red and downregulated probes in green. $\mathbf{b}$ Supervised clustering of differentially selected probes. T1D type 1 diabetes 


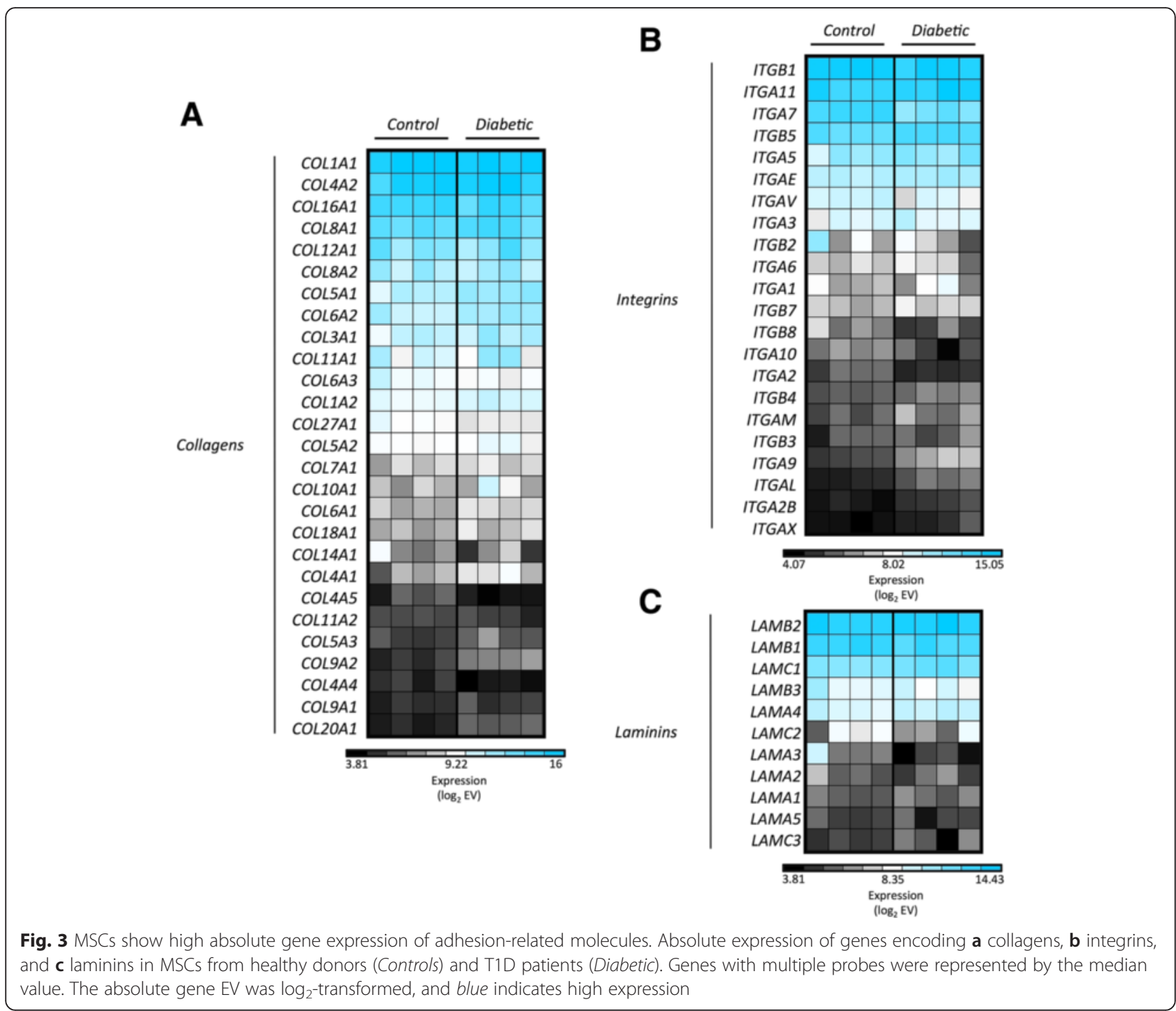

Chemokines and their receptors are key molecules for such activities [62]. Thus, we determined the absolute gene expression of chemokines and chemotaxis-related molecules in T1D-MSCs and C-MSCs. Our analyses detected increased absolute expression of genes encoding CXCL12, CCL24, chemokine-like factor (CKLF), CXCL5, and, especially, CCL2 (MCP-1) in MSCs from both groups (Fig. 5a). Among the chemokine receptors, CXCR3 was mostly expressed (Fig. 5b). Additionally, CXCL12, CCL2, CCL24, and CXCL5 were downregulated in T1D-MSCs compared with C-MSCs (Fig. 5c). Downregulation of CXCL12 was confirmed by real-time PCR (Fig. 5d). Furthermore, despite having low absolute expression $(E V<120)$, genes encoding the chemokines CCL13, CCL15, CXCL16, and CCL3L3 and receptors CCR3, CXCR5, and Duffy antigen/chemokine receptor (DARC) were upregulated in T1D-MSCs compared with their healthy counterparts. Conversely, CCL7 was downregulated (Fig. 5c).

\section{Differential expression of genes encoding cytokines, growth factors, cytokine/growth factor receptors, and} matrix metallopeptidases

Cytokines and matrix metallopeptidase (MMP)-related molecules play a fundamental role in MSC-mediated immune regulation, in tissue regeneration, and also in MSC migration [62]. These functions are also associated with the expression of receptors on the surface of the MSCs, including the "licensing" receptors for IFN- $\gamma$ and TNF- $\alpha$ [29]. In our analysis, both C-MSCs and T1DMSCs presented increased absolute expression of genes encoding cytokines (IL-6, TGF- $\beta 1$ ), growth factors (platelet-derived growth factor (PDGF), vascular endothelial growth factor (VEGF), fibroblastic growth factor 


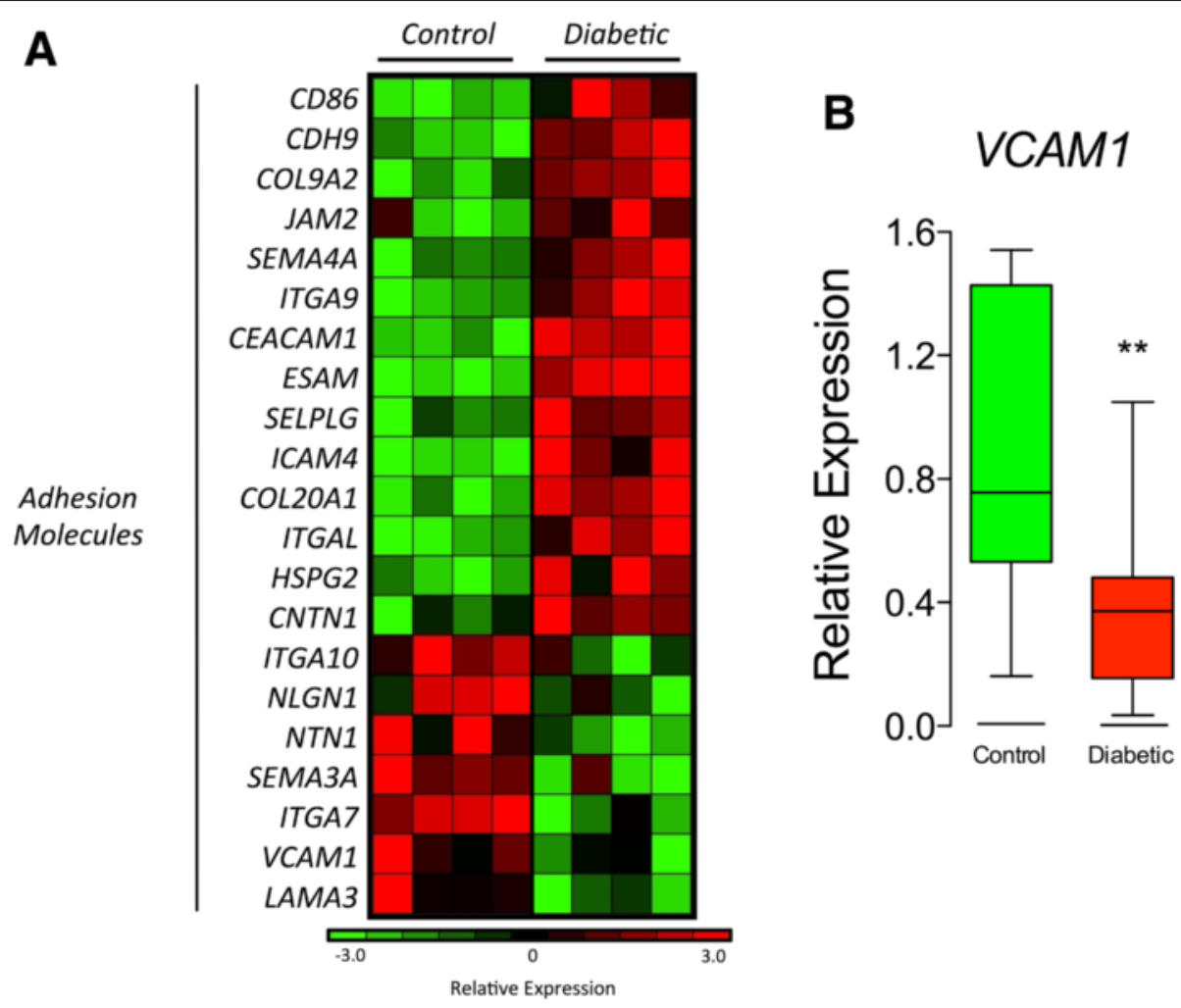

Fig. 4 VCAM-1 and other adhesion-related molecules are differentially regulated in T1D-MSCs. a Heatmap of adhesion-related genes differentially expressed between MSCs from healthy donors (Controls, $n=4$ ) and T1D patients (Diabetic, $n=4)(F C>2, p<0.05$, Student $t$ test, Benjamini Hochberg correction). Upregulated genes are shown in red and downregulated genes in green. $\mathbf{b}$ Relative expression of VCAM1 by real-time PCR (Diabetic, $n=7$; Control, $n=6$ ). Mann-Whitney $U$ test, $p=0.0041$. VCAM-1 vascular cell adhesion protein 1

(FGF), HGF) and MMP-related molecules such as MMP-2, MMP-9, and MT1-MMP (Fig. 6).

Further analysis revealed 24 genes encoding cytokines or growth factors, 17 receptors for these molecules, and nine MMP-related proteins differentially expressed between T1D-MSCs and C-MSCs. Of these, FGF3 and HGF (Fig. 7a), as well as EGFR and FGFR1 (Fig. 7b), were downregulated in T1D-MSCs, while MT1-MMP (MMP14) and MMP2 were upregulated in T1D-MSCs (Fig. 7c), when compared with their healthy counterparts. Both MMP14 and MMP2 are related to MSC migratory capacity. Indeed, we observed higher migratory capacity in MSCs from T1D patients than in those from healthy controls (Additional file 5: Figure S3).

\section{Hyperactivation of sympathetic nervous system signaling in T1D-MSCs}

Signature sequence probe lists were analyzed by collating genes into functional pathways in the KEGG database and ranking those pathways on the basis of statistical overrepresentation with the DAVID bioinformatics database and GSEA. DAVID analysis of the upregulated genes revealed enrichment of the neuroactive ligand-receptor interaction canonical pathway in T1DMSCs (Additional file 6: Table S3). The same pathway was also significantly and positively correlated with T1D-MSCs in the GSEA analysis (Fig. 8a,b). The neuroactive ligand-receptor interaction pathway signaling is triggered by activation of $\mathrm{G}$ protein-coupled receptors that indirectly regulate opening and closing of ion channels after neurotransmitter binding [63]. When examining genes contained in this pathway, we found important upregulation of the $\beta_{3}$-adrenergic receptor-encoding gene $(A D R B 3)$, suggesting activation of the adrenergic system in T1D-MSCs (Fig. 8c).

To further investigate the hyperactivation of the adrenergic system, we then analyzed the expression of downstream genes involved in the $\beta_{3}$-adrenergic signaling. For this purpose, we imported the data of differentially expressed probes into the IPA software and, as expected, most of the $G$ protein-coupled receptor canonical pathway genes were upregulated (Fig. 9).

\section{Discussion}

In the bone marrow, MSCs are in close contact with HSCs and express several factors responsible for the 


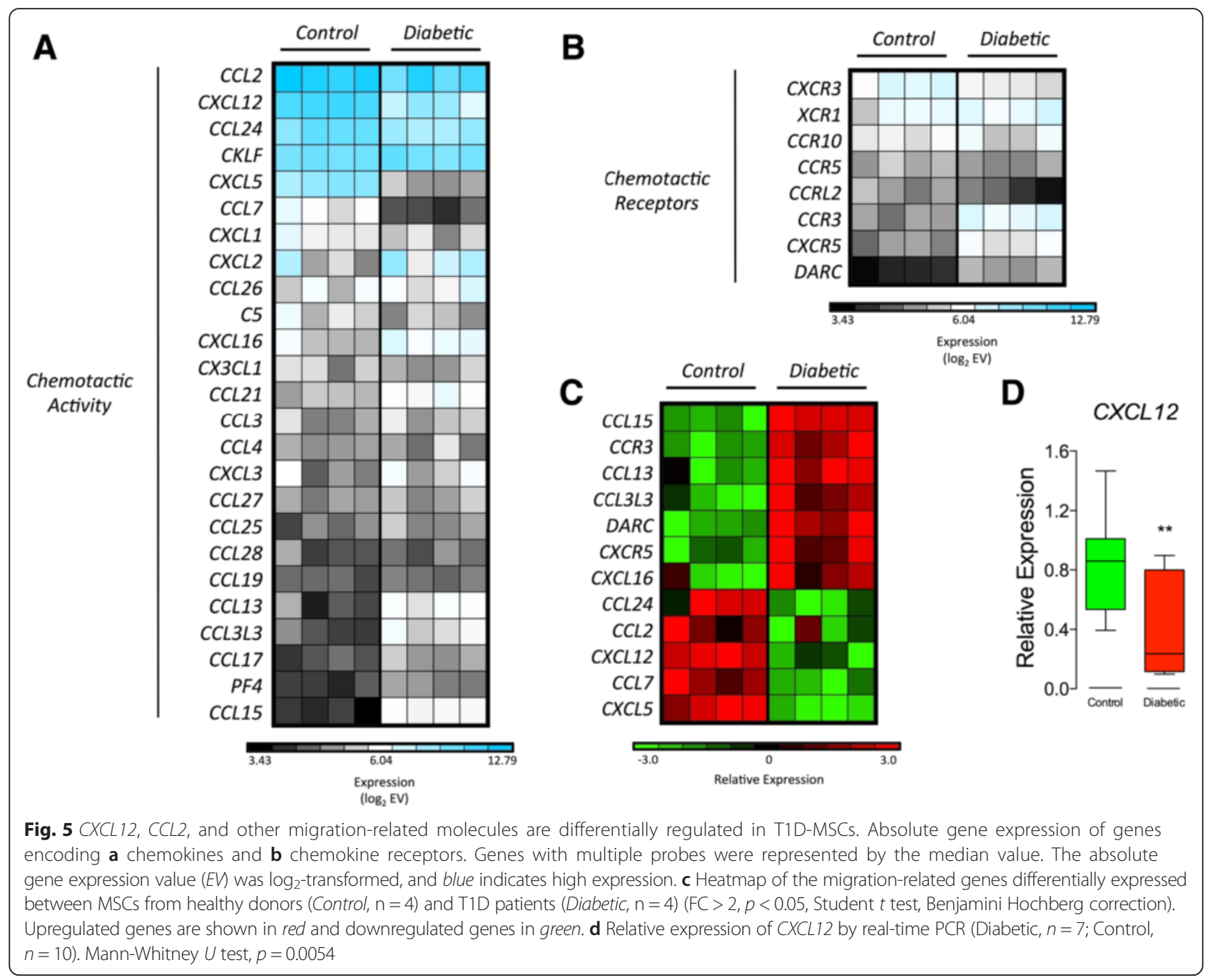

innate and adaptive immune cell maturation and support [64]. Additionally, in-vitro expanded MSCs isolated from bone marrow samples are able to modulate the immune system and have been investigated as treatment for several immune-mediated disorders [5]. However, it remains a matter of debate whether autologous or allogeneic MSCs are more suitable for therapeutic purposes in this context. On one hand, functionally compromised autologous MSCs may be therapeutically ineffective. On the other, allogeneic MSCs may be rejected by the host competent immune system [41].

Here, we demonstrate that in-vitro expanded T1DMSCs present similar morphology, immunophenotype, and multipotential differentiation when compared with MSCs derived from healthy controls. However, our transcriptome analysis revealed more than 2000 probes differentially expressed between T1D-MSCs and C-MSCs.

Cellular function is a consequence of the interaction between DNA sequence, epigenetic status, mRNA and
miRNA expression, and protein content, among other components. Although gene expression analysis offers limited information and some reports have shown notoriously poor correlation between mRNA and protein expression levels, it has been described that differentially expressed mRNAs correlate significantly better with their protein product than nondifferentially expressed mRNAs [65]. Thus, although in our study an absence of validation by other methods or functional experiments is a limitation, we believe that global transcriptomic analysis is a strong enough method to identify markers, including molecular pathways, surface receptors, and secreted factors, for further detailed studies.

Studies addressing potential abnormalities in MSCs derived from patients with autoimmune or inflammatory disorders are scarce and somewhat contradictory. While some authors report phenotypic, proliferative, and genetic abnormalities in cells derived from diseased patients, others describe them as nondifferent from their healthy 


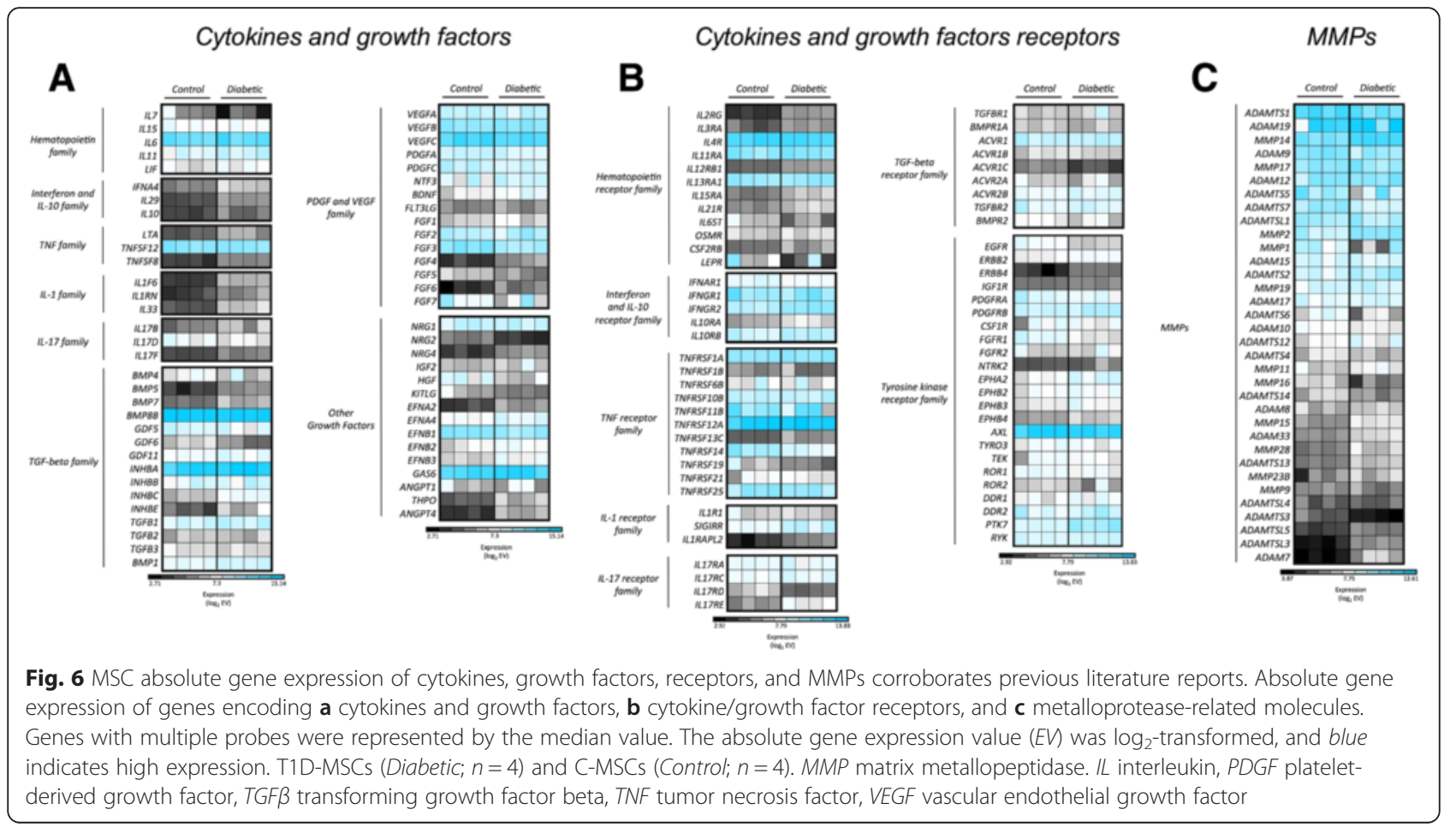

counterparts [45-54]. Expressions of the TGF- $\beta$ receptor gene and protein were found defective in MSCs from SSc patients [46], and $I L-6$ and $I L-7$ mRNA were downregulated in MSCs from SLE patients [48]. Mesenchymal cells derived from the skin of psoriasis patients produced more angiogenic and proinflammatory mediators and showed reduced antioxidant capacity when compared with those isolated from control specimens [51]. Microarray and genome-wide promoter methylation analyses revealed that skin-derived MSCs from psoriasis patients presented aberrant proliferative activity and increased apoptosis rates, markedly different from healthy control MSCs [52-54]. Recently, our group demonstrated genetic and functional alterations in MSCs isolated from MS patients (MS-MSCs) [50]. MS-MSCs in culture presented a senescent phenotype and reduced antiproliferative potential. In addition, microarray analysis showed 618 differentially expressed genes, including downregulation of TGFB1 and HGF. Together, these results indicate that alterations may be disease specific and that abnormalities can involve different aspects of MSC function or morphology.

To provide better understanding of the potential molecules expressed by MSCs and to evaluate which of these were differentially expressed between T1D-MSCs and CMSCs, we matched the absolute and differential gene expression of several adhesion molecules, immune mediators, and growth factors and their receptors. Such analyses allowed us to identify the most relevant differentially expressed molecules, considering the biology of MSCs. Our gene expression data corroborated previous reports, while revealing new molecules potentially related to bone marrow MSC function. As expected, MSCs from both groups of patients (T1D-MSCs and C-MSCs) presented high absolute expression of several well-described adhesion molecules, such as collagen VI [66], laminin-5 [67], integrins [68], fibronectin-1, and intercellular adhesion molecule-1 (ICAM-1) [69]. Additionally, in accordance with the literature, other important molecules were also found highly expressed in our analysis, such as VEGF [70-73], PDGF [73], FGF-2 [74, 75], HGF [70, 72, 76, 77], and the licensing receptors for IFN- $\gamma$ and TNF [29, 31, 40, 78-80].

Focusing on the differential gene expression of immunoregulatory molecules between T1D-MSCs and CMSCs, we found that vascular cell adhesion molecule-1 (VCAM-1) was downregulated in MSCs from T1D patients. Previous reports have shown that under inflammatory stimuli, MSCs produce large amounts of chemokines and upregulate VCAM-1 expression, which interacts with very late antigen-4 (VLA-4), rendering MSCs more adhesive to activated T cells [29]. This close proximity is pivotal for the immunosuppressive effect of MSCs [31]. Our results therefore suggest that this cell contact-dependent suppressive function of MSCs may be impaired in T1D patients.

We observed downmodulation of the HGF gene in T1D-MSCs. Indeed, HGF is also less expressed by bone 


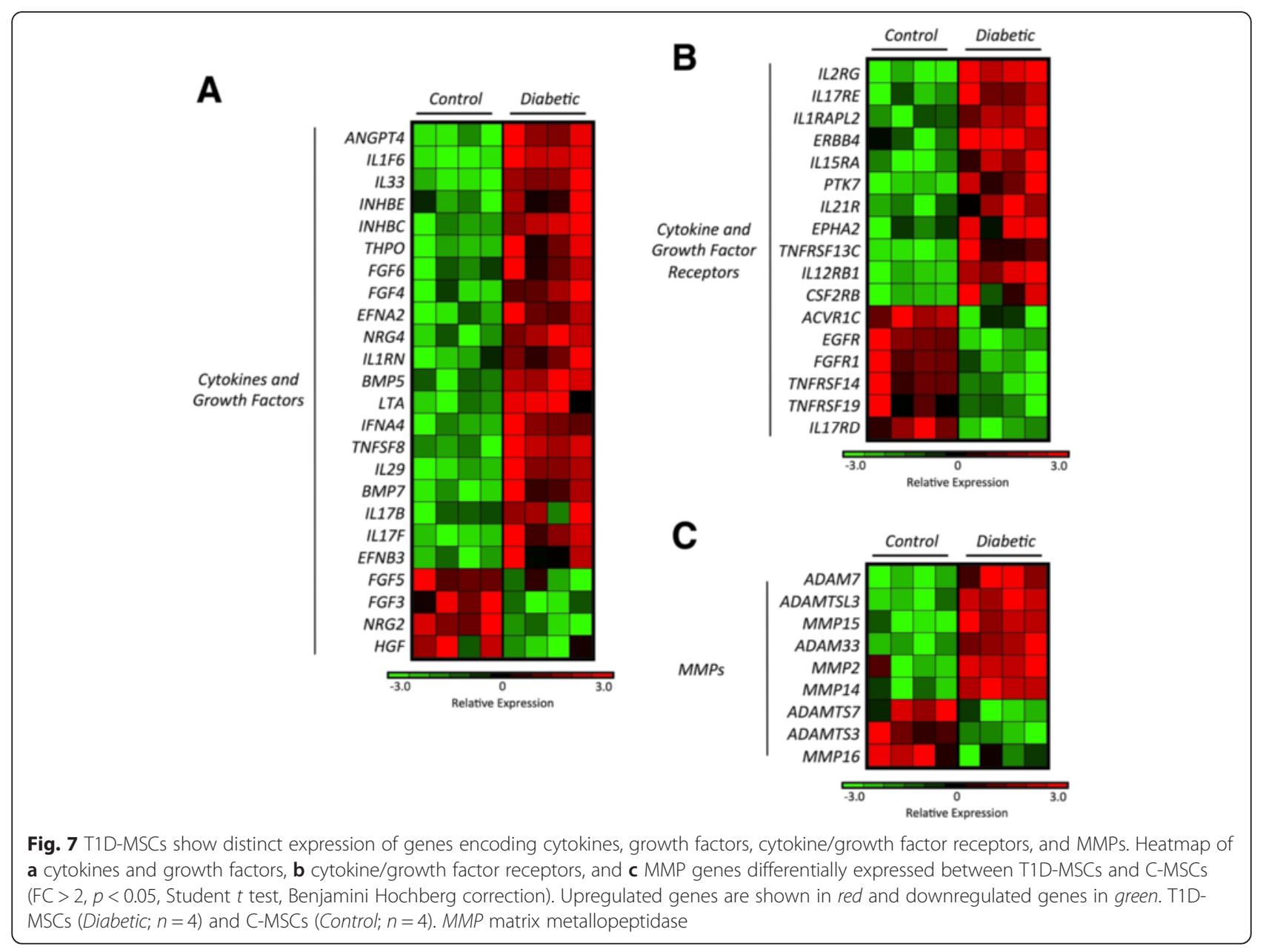

marrow MSCs isolated from MS patients [50]. This pleiotropic cytokine that binds the tyrosine kinase transmembrane receptor c-Met [81] is associated with angiogenesis and cell survival [82, 83]. Injections of HGF stimulate kidney and liver regeneration, and prevent the onset of renal failure [84]. In experimental autoimmune encephalomyelitis (EAE) models, HGF secreted by MSCs promotes neural cell development and remyelination [85]. Interestingly, HGF is also suggested to be a cytoprotective factor for pancreatic $\beta$ cells $[21,86,87]$, and streptozotocin (STZ)-induced insulitis is observed to a higher degree in c-Met null mice than in wild-type littermates [88]. The HGF/c-Met signaling pathway is considered important for $\beta$-cell protection and proliferation in conditions of metabolic stress [89]. Thus, the observed downregulation of HGF in MSCs from T1D patients may indicate a decreased potential for pancreatic regeneration. Additionally, genes encoding the receptors epidermal growth factor receptor (EGFR) and fibroblastic growth factor receptor (FGFR) were also found downregulated in our T1D-MSCs. These receptors regulate stemness, and inhibit senescence, and are essential for cell growth, tissue repair, and homeostasis [90, 91]. Interestingly, EGFR signaling increases secretion of HGF [90, 92, 93]. We believe that downmodulation of $H G F$ in T1D-MSCs may be a result of decreased EGFR signaling.

Moreover, membrane type 1-matrix metalloproteinase (MT1-MMP) and MMP2, whose encoding genes were found upregulated in T1D-MSCs, are essential for the invasive capacity of MSCs [94-102]. Interestingly, T1DMSCs present higher migration capacity than C-MSCs. On the other hand, we detected downregulation of genes encoding CCL2, which is an important regulator of bone marrow monocyte emigration [103]. In EAE mice, the metalloproteinase-mediated paracrine proteolysis of CCL2 is key for the efficacy of murine MSC-based therapy. Indeed, MSCs that are CCL2-deficient have impaired ability to suppress IL-17 production by activated $\mathrm{T}$ cells and, in consequence, lose their protective effect $[104,105]$. It has been described that MSCs cultured alone without cytokines produce minimal amounts of chemokines, and that unprimed MSCs cannot attract T cells [29]. Of note, our study analyzed MSCs after 


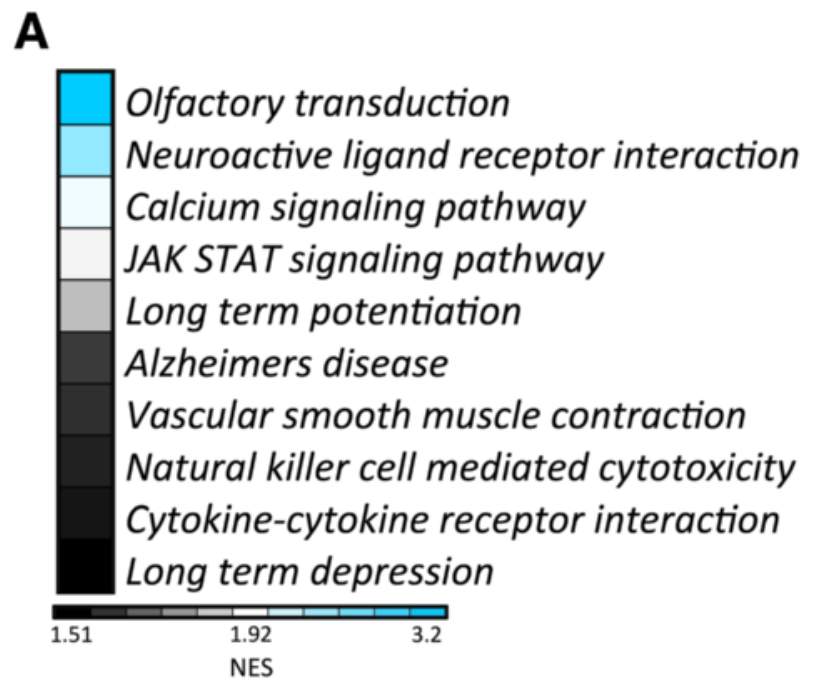

B

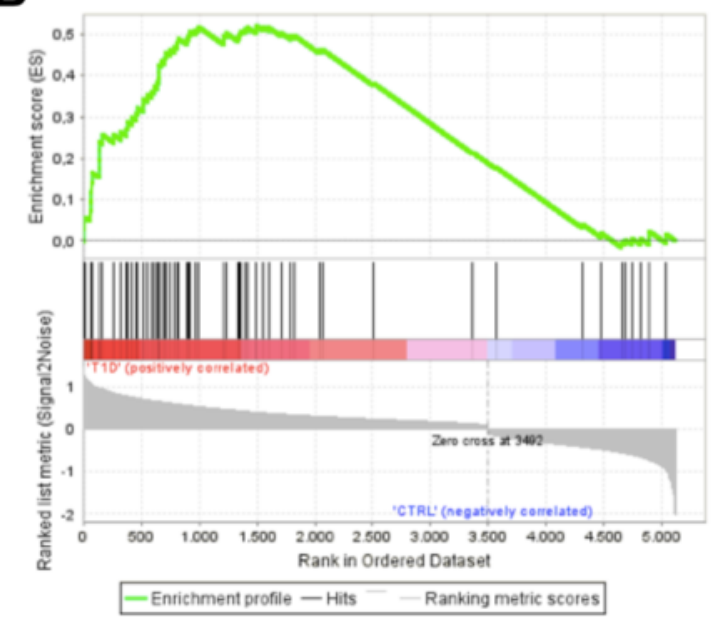

C

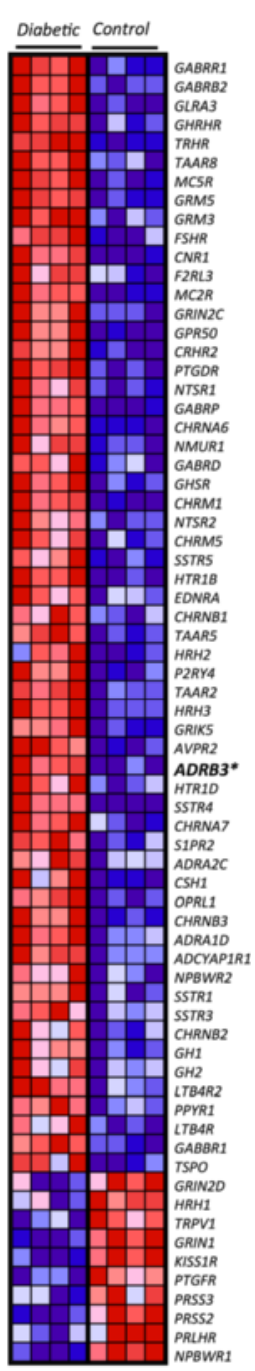

Fig. 8 Pathway analysis suggesting hyperactivation of sympathetic nervous system signaling in T1D-MSCs. GSEA analysis of differentially expressed probes between T1D-MSCs and C-MSCs. a Enrichment analysis in KEGG pathways positively correlated with T1D-MSCs relative to C-MSCs; blue indicates KEGG pathways with higher normalized enrichment score (NES). Only data sets with $p<0.05$ and FDR $>0.25$ are shown. $\mathbf{b}$ Enrichment plot of the neuroactive ligand-receptor interaction KEGG pathway: green curve indicates the enrichment score (ES); black vertical dashed lines specify the maximum enrichment score. $\mathbf{c}$ Heatmap showing expression of genes in the leading edge subsets. The ADRB3 gene is shown in bold. Diabetic T1D-MSCs, Control C-MSCs

culturing and we were not able to determine whether these changes are related to culturing conditions beyond their exposure to the altered diabetic bone marrow milieu. How these gene expression alterations may affect therapeutic efficacy of bone marrow MSCs of T1D patients remains unknown and further functional experiments are still warranted.

Finally, to identify previously unknown immunologically relevant pathways associated with T1D-MSCs, we uploaded the differentially expressed genes into DAVID and GSEA bioinformatics databases. We detected preferential enrichment of canonical pathways related to sympathetic hyperactivity and also upregulation of the $\beta_{3}$-adrenergic receptor gene $A D R B 3$ in T1D-MSCs. In the bone marrow, nerve fibers that are physically associated with MSCs contribute to the circadian oscillation of HSC mobilization [6, 106, 107]. This event is mainly controlled by sympathetic nervous system (SNS) signaling through the expression of $\beta_{3}$-adrenergic receptors in bone marrow MSCs, and negatively regulates important HSC maintenance factors, such as CXCL12 and VCAM-1 [6]. T1D patients present bone marrow abnormalities, and are poor HSC mobilizers [108-111]. Indeed, STZ-induced diabetes mice present aberrant SNS 


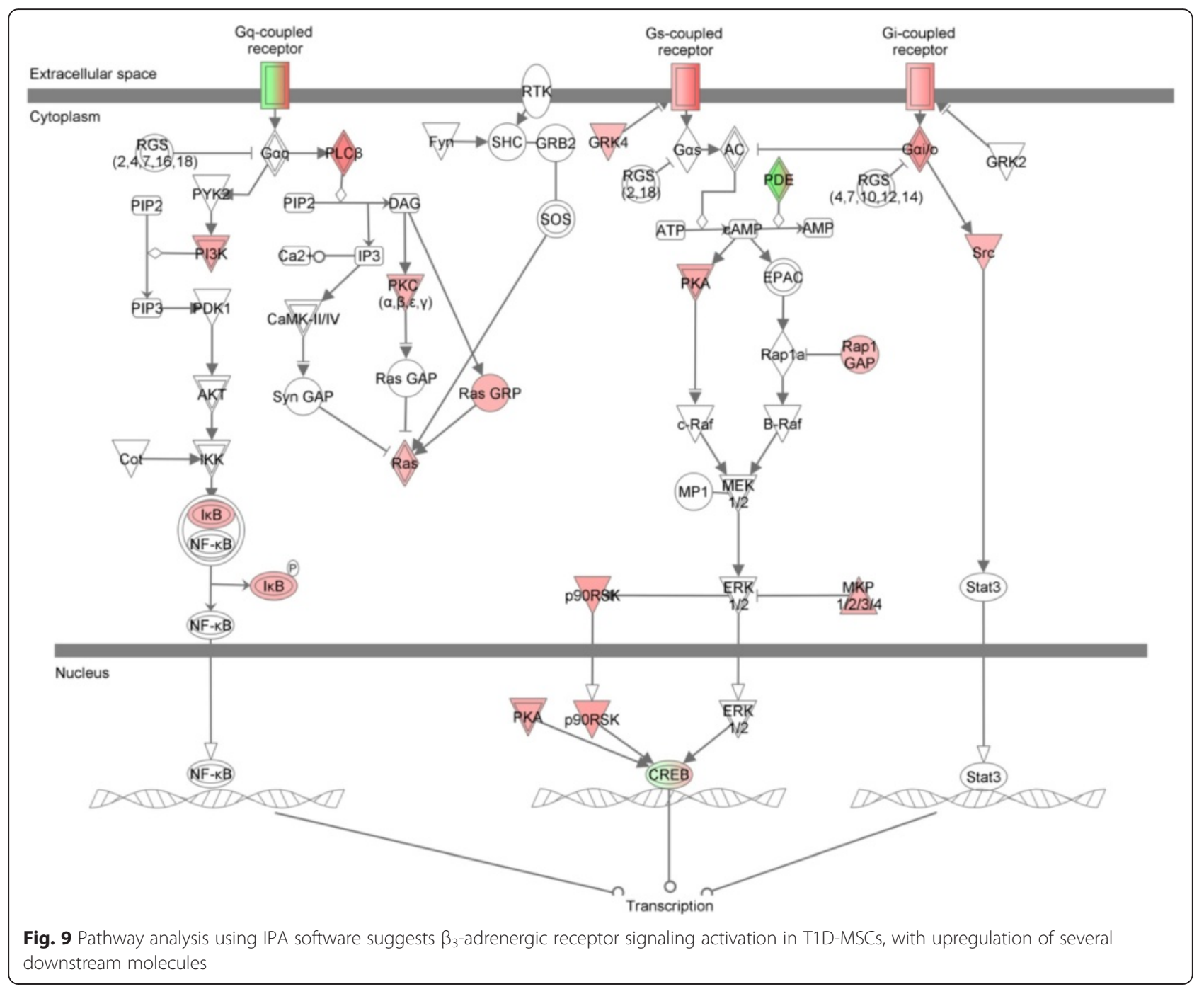

signaling in the bone marrow, with impaired expression of CXCL12 [109]. In line with these literature reports, our differential microarray analysis showed downregulation of both HSC maintenance molecules, CXCL12 and VCAM1, in T1D-MSCs.

\section{Conclusions}

Collectively, our findings demonstrate that bone marrow MSCs isolated from newly-diagnosed T1D patients have similar morphology, immunophenotypic profiling, and multipotential differentiation when compared with MSCs from healthy subjects. However, microarray analysis revealed several intrinsic abnormalities in their mRNA expression. MSCs from T1D patients presented enriched canonical pathways related to sympathetic innervation and consequent SNS signaling hyperactivity, with increase of $\beta_{3}$-adrenergic receptor gene expression. To our knowledge, this is the first report of transcriptional profiling of MSCs isolated from the bone marrow of T1D patients. The implications of these intrinsic genetic alterations in T1D development as well as in the therapeutic efficacy of autologous MSC transplantation require further investigation.

\section{Additional files}

Additional file 1: Table S1. Presenting clinical characteristics of T1D patients at inclusion. (DOCX $49 \mathrm{~kb}$ )

Additional file 2: Table S2. Showing hierarchical cluster analysis with AU/BP values. The cluster analysis was performed using the pvclust $R$ package. Clusters with $\mathrm{AU}>95 \%$ are highlighted by rectangles, which are strongly supported by data. $A U$ approximately unbiased $p$ value, $B P$ bootstrap probability value, D-PRE T1D-MSCs, CTRL C-MSCs. (TIFF $83966 \mathrm{~kb}$ )

Additional file 3: Figure S1. Presenting comparison of surface antigen expression in T1D-MSCs and C-MSCs. (DOCX 65 kb)

Additional file 4: Figure S2. Showing MSCs present high absolute gene expression of other adhesion-related molecules. Genes with multiple probes are represented by the median value, in T1D-MSCs (Diabetic) and C-MSCs (Contro). Only genes with high absolute gene expression are shown. The EV was $\log _{2}$-transformed. (TIFF $108909 \mathrm{~kb}$ ) 
Additional file 5: Figure S3. Showing T1D-MSCs have higher motility after in-vitro migration assay. (A) Representative images of transwell migration assay using $50 \%$ FBS as chemoattractant, showing Giemsastained MSCs from healthy individuals (C-MSCs, left) and from T1D patients (T1D-MSCs, right). (B) The fraction of cells that migrated across $8 \mu \mathrm{m}$ diameter pores over $6 \mathrm{~h}$ was counted in seven different fields using light microscopy. Bars represent means \pm SEM. ${ }^{*} p<0.05$. 200x magnification. (TIFF $50715 \mathrm{~kb}$ )

Additional file 6: Table S3. Presenting DAVID analysis of the upregulated genes. (DOCX $53 \mathrm{~kb}$ )

\section{Abbreviations}

a-MEM, minimum essential medium alpha; BRITE, binary relationships of biological entities; C-MSC, bone marrow-derived MSC isolated from healthy donors (controls); CKLF, chemokine-like factor; COX2, cyclooxygenase-2; CXCL12, (C-X-C motif) ligand 12 chemokine; DAVID, Database for Annotation, Visualization and Integrated Discovery; EAE, experimental autoimmune encephalomyelitis; ECM, extracellular matrix; EDTA, ethylenediamine tetraacetic acid; EGFR, epidermal growth factor receptor; EV, expression value; FBS, fetal bovine serum; FC, fold change; FDR, false discovery rate; FGF, fibroblast growth factor; FGFR, fibroblast growth factor receptor; GAD, glutamate decarboxylase; GAPDH, glyceraldehyde 3-phosphate dehydrogenase; GSEA, gene set enrichment analysis; GvHD, graft-versushost disease; HGF, hepatocyte growth factor, HLA, human leukocyte antigen; HSC, hematopoietic stem cell; IDO, indoleamine 2,3-dioxygenase; IFN- $\gamma$, interferon gamma; IFN- $\mathrm{R} 1$, interferon gamma receptor 1 ; IL, interleukin; IPA, ingenuity pathway analysis; KEGG, Kyoto Encyclopedia of Genes and Genomes; LIMMA, linear models for microarray data; MCP-1, monocyte chemoattractant protein-1; MHC, major histocompatibility complex; MMP, matrix metallopeptidase; MS, multiple sclerosis; MSC, multipotent mesenchymal stromal cell; NOD/SCID, nonobese/severe combined immunodeficiency; PDGF, platelet-derived growth factor; PDGFR, platelet-derived growth factor receptor; RA, rheumatoid arthritis; SLE, systemic lupus erythematosus; SNS, sympathetic nervous system; SSC, systemic sclerosis; STZ, streptozotocin; T1D-MSC, bone marrowderived MSC isolated from T1D patients; T1D, type 1 diabetes; TGF $\beta-1$, transforming growth factor beta 1; TNF, tumor necrosis factor; TNFR1, tumor necrosis factor receptor superfamily member $1 \mathrm{~A}$; Treg, T regulatory cell; VCAM-1, vascular cell adhesion protein 1; VEGF, vascular endothelial growth factor; VLA-4, very late antigen-4

\section{Acknowledgements}

This work was supported by research grants from by the following Brazilian institutions: National Council for Scientific and Technological Development (CNPq), São Paulo Research Foundation (FAPESP), and Agency for the Support and Evaluation of Graduate Education (CAPES).

\section{Authors' contributions}

KAdL participated in all aspects of the study, experimental conception and design, data acquisition, data analysis, interpretation, and manuscript writing. KCRM and JCV contributed to conception and study design, and data analysis and interpretation. KCRM and MCO participated in drafting/revising the manuscript. GLVdO participated in the sample collection, interpretation of data, and drafting/revising the manuscript. JNUY carried out the MSC phenotypical characterization, data analysis and interpretation, and drafting/revising of the manuscript. JTCdA performed quantitative real-time PCR experiments, data analysis, and drafting/revising of the manuscript. WASJ and DGP participated in the acquisition, analysis, discussion, and interpretation of microarray analysis, and reviewed the manuscript. JCV, BPS, CEBC, and MCO were responsible for sample collection, discussion of results, clinical characterization of T1D patients, and drafting/revising of the manuscript. DTC provided administrative support, and drafting/revising of the manuscript. All authors read and approved the final manuscript.

\section{Competing interests}

The authors declare that they have no competing interests.

\section{Author details}

${ }^{1}$ Center for Cell-Based Research, Regional Blood Center of Ribeirao Preto, Ribeirao Preto Medical, University of Sao Paulo, Ribeirao Preto, Brazil.
${ }^{2}$ Department of Biochemistry and Immunology, Ribeirao Preto Medical School, University of Sao Paulo, Ribeirao Preto, Brazil. ${ }^{3}$ Department of Clinical and Toxicological Analysis, Federal University of Ceará, Fortaleza, Ceara, Brazil. ${ }^{4}$ Department of Clinical Medicine, Ribeirao Preto Medical School, University of Sao Paulo, Ribeirao Preto, Brazil. ${ }^{5}$ Department of Clinical, Toxicological and Bromatological Analysis, Faculty of Pharmaceutical Sciences of Ribeirao Preto, University of Sao Paulo, Ribeirao Preto, Brazil. ${ }^{\top}$ Tenente Catao Roxo, 2501, Monte Alegre, 14051-140 Ribeirao Preto, Sao Paulo, Brazil.

\section{Received: 22 December 2015 Revised: 12 April 2016} Accepted: 22 June 2016 Published online: 12 July 2016

\section{References}

1. Nombela-Arrieta C, Ritz J, Silberstein LE. The elusive nature and function of mesenchymal stem cells. Nat Rev Mol Cell Biol. 2011;12:126-31.

2. Friedenstein AJ, Piatetzky-Shapiro II, Petrakova KV. Osteogenesis in transplants of bone marrow cells. J Embryol Exp Morphol. 1966;16:381-90.

3. Friedenstein AJ, Petrakova KV, Kurolesova Al, et al. Heterotopic of bone marrow. Analysis of precursor cells for osteogenic and hematopoietic tissues. Transplantation. 1968;6:230-47.

4. Ma S, Xie N, Li W, et al. Immunobiology of mesenchymal stem cells. Cell Death Differ. 2014;21:216-25.

5. Wang Y, Chen X, Cao W, et al. Plasticity of mesenchymal stem cells in immunomodulation: pathological and therapeutic implications. Nat Immunol. 2014;15:1009-16.

6. Méndez-Ferrer S, Michurina TV, Ferraro F, et al. Mesenchymal and haematopoietic stem cells form a unique bone marrow niche. Nature. 2010;466:829-34.

7. Isern J, Méndez-Ferrer S. Stem cell interactions in a bone marrow niche. Curr Osteoporos Rep. 2011;9:210-8.

8. Frenette PS, Pinho S, Lucas D et al. Mesenchymal stem cell: keystone of the hematopoietic stem cell niche and a stepping-stone for regenerative medicine. Annu Rev Immunol. 2013;31:285-316. doi:10.1146/annurevimmunol-032712-095919.

9. Mendelson A, Frenette PS. Hematopoietic stem cell niche maintenance during homeostasis and regeneration. Nat Med. 2014;20:833-46.

10. Uccelli A, Moretta L, Pistoia V. Mesenchymal stem cells in health and disease. Nat Rev Immunol. 2008;8:726-36.

11. Krampera M, Glennie S, Dyson J, et al. Bone marrow mesenchymal stem cells inhibit the response of naive and memory antigen-specific $T$ cells to their cognate peptide. Blood. 2003;101:3722-9.

12. Bartholomew A, Sturgeon C, Siatskas M, et al. Mesenchymal stem cells suppress lymphocyte proliferation in vitro and prolong skin graft survival in vivo. Exp Hematol. 2002;30:42-8.

13. Di Nicola M, Carlo-Stella C, Magni M, et al. Human bone marrow stromal cells suppress T-lymphocyte proliferation induced by cellular or nonspecific mitogenic stimuli. Blood. 2002;99:3838-43.

14. Le Blanc K, Mougiakakos D. Multipotent mesenchymal stromal cells and the innate immune system. Nat Rev Immunol. 2012;12:383-96.

15. Abdi R, Fiorina P, Adra CN, et al. Immunomodulation by mesenchymal stem cells: a potential therapeutic strategy for type 1 diabetes. Diabetes. 2008;57:1759-67.

16. Le Blanc K, Ringdén O. Immunomodulation by mesenchymal stem cells and clinical experience. J Intern Med. 2007;262:509-25.

17. Fiorina P, Voltarelli J, Zavazava N. Immunological applications of stem cells in type 1 diabetes. Endocr Rev. 2011;32:725-54.

18. Couri CE, Voltarelli JC. Stem cell-based therapies and immunomodulatory approaches in newly diagnosed type 1 diabetes. Curr Stem Cell Res Ther. 2011;6:10-5.

19. Lee RH, Seo MJ, Reger RL, et al. Multipotent stromal cells from human marrow home to and promote repair of pancreatic islets and renal glomeruli in diabetic NOD/scid mice. Proc Natl Acad Sci U S A. 2006;103:17438-43.

20. Zhao W, Wang Y, Wang D, et al. TGF-beta expression by allogeneic bone marrow stromal cells ameliorates diabetes in NOD mice through modulating the distribution of CD4+ T cell subsets. Cell Immunol. 2008;253:23-30.

21. Boumaza I, Srinivasan S, Witt WT, et al. Autologous bone marrow-derived rat mesenchymal stem cells promote PDX-1 and insulin expression in the islets, alter T cell cytokine pattern and preserve regulatory $T$ cells in the periphery and induce sustained normoglycemia. J Autoimmun. 2009;32:33-42.

22. Bassi EJ, Moraes-Vieira PM, Moreira Sá CS et al. Immune regulatory properties of allogeneic adipose-derived mesenchymal stem cells in the 
treatment of experimental autoimmune diabetes. Diabetes. 2012;61(10): 2534-45. http://dx.doi.org/10.2337/db11-0844.

23. Madec AM, Mallone R, Afonso G, et al. Mesenchymal stem cells protect NOD mice from diabetes by inducing regulatory T cells. Diabetologia. 2009;52:1391-9.

24. Bernardo ME, Locatelli F, Fibbe WE. Mesenchymal stromal cells. Ann N Y Acad Sci. 2009;1176:101-17.

25. Liu H, Kemeny DM, Heng BC, et al. The immunogenicity and immunomodulatory function of osteogenic cells differentiated from mesenchymal stem cells. J Immunol. 2006;176:2864-71.

26. Le Blanc K, Ringdén O. Immunobiology of human mesenchymal stem cells and future use in hematopoietic stem cell transplantation. Biol Blood Marrow Transplant. 2005;11:321-34.

27. Parekkadan B, Milwid JM. Mesenchymal stem cells as therapeutics. Annu Rev Biomed Eng. 2010;12:87-117.

28. Li W, Ren G, Huang Y, et al. Mesenchymal stem cells: a double-edged sword in regulating immune responses. Cell Death Differ. 2012;19:1505-13.

29. Ren G, Zhang L, Zhao X, et al. Mesenchymal stem cell-mediated immunosuppression occurs via concerted action of chemokines and nitric oxide. Cell Stem Cell. 2008;2:141-50.

30. Ren G, Su J, Zhang $L$, et al. Species variation in the mechanisms of mesenchymal stem cell-mediated immunosuppression. Stem Cells. 2009:27:1954-62

31. Ren $G$, Zhao X, Zhang $L$, et al. Inflammatory cytokine-induced intercellular adhesion molecule-1 and vascular cell adhesion molecule-1 in mesenchymal stem cells are critical for immunosuppression. J Immunol. 2010;184:2321-8.

32. Shi Y, Su J, Roberts Al, et al. How mesenchymal stem cells interact with tissue immune responses. Trends Immunol. 2012;33:136-43.

33. Dazzi F, Marelli-Berg FM. Mesenchymal stem cells for graft-versus-host disease: close encounters with T cells. Eur J Immunol. 2008;38:1479-82.

34. Annunziato F, Cosmi L, Liotta F, et al. Type $17 \mathrm{~T}$ helper cells-origins, features and possible roles in rheumatic disease. Nat Rev Rheumatol. 2009;5:325-31.

35. Polchert D, Sobinsky J, Douglas G, et al. IFN-gamma activation of mesenchymal stem cells for treatment and prevention of graft versus host disease. Eur J Immunol. 2008;38:1745-55.

36. Chan JL, Tang KC, Patel AP, et al. Antigen-presenting property of mesenchymal stem cells occurs during a narrow window at low levels of interferon-gamma. Blood. 2006:107:4817-24.

37. Stagg J, Pommey S, Eliopoulos N, et al. Interferon-gamma-stimulated marrow stromal cells: a new type of nonhematopoietic antigen-presenting cell. Blood. 2006;107:2570-7.

38. Stagg J. Immune regulation by mesenchymal stem cells: two sides to the coin. Tissue Antigens. 2007;69:1-9.

39. François M, Romieu-Mourez R, Stock-Martineau S, et al. Mesenchymal stromal cells cross-present soluble exogenous antigens as part of their antigen-presenting cell properties. Blood. 2009;114:2632-8.

40. Krampera M, Cosmi L, Angeli R, et al. Role for interferon-gamma in the immunomodulatory activity of human bone marrow mesenchymal stem cells. Stem Cells. 2006;24:386-98.

41. Griffin MD, Ryan AE, Alagesan S, et al. Anti-donor immune responses elicited by allogeneic mesenchymal stem cells: what have we learned so far? Immunol Cell Biol. 2013;91:40-51.

42. Bernardo ME, Avanzini MA, Ciccocioppo R, et al. Phenotypical/functional characterization of in vitro-expanded mesenchymal stromal cells from patients with Crohn's disease. Cytotherapy. 2009;11:825-36.

43. Kastrinaki MC, Sidiropoulos P, Roche $S$, et al. Functional, molecular and proteomic characterisation of bone marrow mesenchymal stem cells in rheumatoid arthritis. Ann Rheum Dis. 2008;67:741-9.

44. Larghero J, Farge D, Braccini A, et al. Phenotypical and functional characteristics of in vitro expanded bone marrow mesenchymal stem cells from patients with systemic sclerosis. Ann Rheum Dis. 2008;67:443-9.

45. Mallam E, Kemp K, Wilkins A, et al. Characterization of in vitro expanded bone marrow-derived mesenchymal stem cells from patients with multiple sclerosis. Mult Scler. 2010;16:909-18.

46. Vanneaux $V$, Farge-Bancel $D$, Lecourt $S$ et al. Expression of transforming growth factor $\beta$ receptor II in mesenchymal stem cells from systemic sclerosis patients. BMJ Open. 2013;3(1). doi:10.1136/bmjopen-2012-001890.

47. Guiducci S, Manetti M, Romano E, et al. Bone marrow-derived mesenchymal stem cells from early diffuse systemic sclerosis exhibit a paracrine machinery and stimulate angiogenesis in vitro. Ann Rheum Dis. 2011;70:2011-21.

48. Sun LY, Zhang HY, Feng XB, et al. Abnormality of bone marrow-derived mesenchymal stem cells in patients with systemic lupus erythematosus. Lupus. 2007;16:121-8.
49. Nie Y, Lau C, Lie A, et al. Defective phenotype of mesenchymal stem cells in patients with systemic lupus erythematosus. Lupus. 2010;19:850-9.

50. de Oliveira GL, de Lima KW, Colombini AM et al. Bone marrow mesenchymal stromal cells isolated from multiple sclerosis patients have distinct gene expression profile and decreased suppressive function compared with healthy counterparts. Cell Transplant. 2015;24(2):151-65. doi:10.3727/ $096368913 \times 675142$.

51. Orciani M, Campanati A, Salvolini E, et al. The mesenchymal stem cell profile in psoriasis. Br J Dermatol. 2011;165:585-92.

52. Hou R, Yin G, An P, et al. DNA methylation of dermal MSCs in psoriasis: identification of epigenetically dysregulated genes. J Dermatol Sci. 2013;72:103-9.

53. Hou R, Yan H, Niu X, et al. Gene expression profile of dermal mesenchymal stem cells from patients with psoriasis. J Eur Acad Dermatol Venereol. 2014:28:1782-91.

54. Hou R, Liu R, Niu X, et al. Biological characteristics and gene expression pattern of bone marrow mesenchymal stem cells in patients with psoriasis. Exp Dermatol. 2014;23:521-3.

55. Fiorina $\mathrm{P}$, Jurewicz $\mathrm{M}$, Augello $\mathrm{A}$, et al. Immunomodulatory function of bone marrow-derived mesenchymal stem cells in experimental autoimmune type 1 diabetes. J Immunol. 2009:183:993-1004.

56. Ritchie ME, Phipson B, Wu D, et al. LIMMA powers differential expression analyses for RNA-sequencing and microarray studies. Nucleic Acids Res. 2015;43:e47.

57. Reich M, Liefeld T, Gould J, et al. GenePattern 2.0. Nat Genet. 2006;38:500-1.

58. Kanehisa M, Goto S, Sato $Y$ et al. KEGG for integration and interpretation of large-scale molecular data sets. Nucleic Acids Res. 2012;40(Database issue): D109-14. doi:10.1093/nar/gkr988.

59. Huang dW, Sherman BT, Lempicki RA. Bioinformatics enrichment tools: paths toward the comprehensive functional analysis of large gene lists. Nucleic Acids Res. 2009;37:1-13.

60. Huang dW, Sherman BT, Lempicki RA. Systematic and integrative analysis of large gene lists using DAVID bioinformatics resources. Nat Protoc. 2009;4:44-57.

61. Prockop DJ, Oh JY. Mesenchymal stem/stromal cells (MSCs): role as guardians of inflammation. Mol Ther. 2012;20:14-20.

62. Meirelles LS, Fontes AM, Covas DT, et al. Mechanisms involved in the therapeutic properties of mesenchymal stem cells. Cytokine Growth Factor Rev. 2009;20:419-27.

63. Hille B. Modulation of ion-channel function by G-protein-coupled receptors. Trends Neurosci. 1994;17:531-6.

64. Ehninger A, Trumpp A. The bone marrow stem cell niche grows up: mesenchymal stem cells and macrophages move in. J Exp Med. 2011;208:421-8.

65. Koussounadis A, Langdon SP, Um IH, et al. Relationship between differentially expressed mRNA and mRNA-protein correlations in a xenograft model system. Sci Rep. 2015;5:10775.

66. Klein G, Müller CA, Tillet E, et al. Collagen type VI in the human bone marrow microenvironment: a strong cytoadhesive component. Blood. 1995;86:1740-8

67. Hashimoto J, Kariya Y, Miyazaki K. Regulation of proliferation and chondrogenic differentiation of human mesenchymal stem cells by laminin-5 (laminin-332). Stem Cells. 2006:24:2346-54.

68. Semon JA, Nagy LH, Llamas CB, et al. Integrin expression and integrinmediated adhesion in vitro of human multipotent stromal cells (MSCs) to endothelial cells from various blood vessels. Cell Tissue Res. 2010;341:147-58.

69. Wilson A, Trumpp A. Bone-marrow haematopoietic-stem-cell niches. Nat Rev Immunol. 2006:6:93-106.

70. Tögel F, Weiss K, Yang Y, et al. Vasculotropic, paracrine actions of infused mesenchymal stem cells are important to the recovery from acute kidney injury. Am J Physiol Renal Physiol. 2007;292:F1626-35.

71. Rehman J, Traktuev D, Li J, et al. Secretion of angiogenic and antiapoptotic factors by human adipose stromal cells. Circulation. 2004;109:1292-8.

72. Ribeiro CA, Fraga JS, Grãos M, et al. The secretome of stem cells isolated from the adipose tissue and Wharton jelly acts differently on central nervous system derived cell populations. Stem Cell Res Ther. 2012;3:18.

73. Chen L, Tredget EE, Wu PY, et al. Paracrine factors of mesenchymal stem cells recruit macrophages and endothelial lineage cells and enhance wound healing. PLoS One 2008:3:e1886.

74. Zaragosi LE, Ailhaud G, Dani C. Autocrine fibroblast growth factor 2 signaling is critical for self-renewal of human multipotent adipose-derived stem cells. Stem Cells. 2006;24:2412-9. 
75. Rider DA, Dombrowski C, Sawyer AA, et al. Autocrine fibroblast growth factor 2 increases the multipotentiality of human adipose-derived mesenchymal stem cells. Stem Cells. 2008;26:1598-608.

76. Suga $\mathrm{H}$, Eto H, Shigeura T, et al. IFATS collection: Fibroblast growth factor-2induced hepatocyte growth factor secretion by adipose-derived stromal cells inhibits postinjury fibrogenesis through a c-Jun N-terminal kinasedependent mechanism. Stem Cells. 2009;27:238-49.

77. Cai L, Johnstone BH, Cook TG, et al. Suppression of hepatocyte growth factor production impairs the ability of adipose-derived stem cells to promote ischemic tissue revascularization. Stem Cells. 2007;25:3234-43.

78. Ryan JM, Barry F, Murphy JM, et al. Interferon-gamma does not break, but promotes the immunosuppressive capacity of adult human mesenchymal stem cells. Clin Exp Immunol. 2007;149:353-63.

79. English K, Barry FP, Field-Corbett CP, et al. IFN-gamma and TNF-alpha differentially regulate immunomodulation by murine mesenchymal stem cells. Immunol Lett. 2007;110:91-100.

80. Krampera M. Mesenchymal stromal cell "licensing": a multistep process. Leukemia. 2011;25:1408-14.

81. Sheth PR, Hays JL, Elferink LA, et al. Biochemical basis for the functional switch that regulates hepatocyte growth factor receptor tyrosine kinase activation. Biochemistry. 2008;47:4028-38.

82. Sulpice E, Ding S, Muscatelli-Groux B, et al. Cross-talk between the VEGF-A and HGF signalling pathways in endothelial cells. Biol Cell. 2009:101:525-39.

83. Kitamura K, Iwanami A, Nakamura M, et al. Hepatocyte growth factor promotes endogenous repair and functional recovery after spinal cord injury. J Neurosci Res. 2007;85:2332-42.

84. Anan F, Shimomura T, Imagawa M, et al. Predictors for silent cerebral infarction in patients with chronic renal failure undergoing hemodialysis. Metabolism. 2007:56:593-8.

85. Bai L, Lennon DP, Caplan Al, et al. Hepatocyte growth factor mediates mesenchymal stem cell-induced recovery in multiple sclerosis models. Nat Neurosci. 2012;15:862-70.

86. Yeung TY, Seeberger KL, Kin T, et al. Human mesenchymal stem cells protect human islets from pro-inflammatory cytokines. PLoS One. 2012;7:e38189.

87. Alvarez-Perez JC, Ernst S, Demirci C, et al. Hepatocyte growth factor/c-Met signaling is required for $\beta$-cell regeneration. Diabetes. 2014;63:216-23.

88. Mellado-Gil J, Rosa TC, Demirci C, et al. Disruption of hepatocyte growth factor/c-Met signaling enhances pancreatic beta-cell death and accelerates the onset of diabetes. Diabetes. 2011;60:525-36.

89. Mellado-Gil JM, Cobo-Vuilleumier N, Gauthier BR. Islet $\beta$-cell mass preservation and regeneration in diabetes mellitus: four factors with potential therapeutic interest. J Transplant. 2012;2012:230870.

90. Tamama K, Fan VH, Griffith LG, et al. Epidermal growth factor as a candidate for ex vivo expansion of bone marrow-derived mesenchymal stem cells. Stem Cells. 2006;24:686-95.

91. Krampera M, Pasini A, Rigo A et al. HB-EGF/HER-1 signaling in bone marrow mesenchymal stem cells: inducing cell expansion and reversibly preventing multilineage differentiation. Blood. 2005;106(1):59-66. 10.1182/blood-200409-3645.

92. Wang Y, Weil BR, Herrmann JL, et al. MEK, p38, and PI-3 K mediate cross talk between EGFR and TNFR in enhancing hepatocyte growth factor production from human mesenchymal stem cells. Am J Physiol Cell Physiol. 2009;297:C1284-93.

93. De Luca A, Gallo M, Aldinucci D, et al. Role of the EGFR ligand/receptor system in the secretion of angiogenic factors in mesenchymal stem cells. J Cell Physiol. 2011;226:2131-8.

94. Ries C, Egea V, Karow M, et al. MMP-2, MT1-MMP, and TIMP-2 are essential for the invasive capacity of human mesenchymal stem cells: differential regulation by inflammatory cytokines. Blood. 2007;109:4055-63.

95. Son BR, Marquez-Curtis LA, Kucia M, et al. Migration of bone marrow and cord blood mesenchymal stem cells in vitro is regulated by stromal-derived factor-1-CXCR4 and hepatocyte growth factor-c-met axes and involves matrix metalloproteinases. Stem Cells. 2006;24:1254-64.

96. Cao J, Sato H, Takino T, et al. The C-terminal region of membrane type matrix metalloproteinase is a functional transmembrane domain required for pro-gelatinase A activation. J Biol Chem. 1995;270:801-5.

97. Al-Raawi D, Abu-El-Zahab H, El-Shinawi M, et al. Membrane type-1 matrix metalloproteinase (MT1-MMP) correlates with the expression and activation of matrix metalloproteinase-2 (MMP-2) in inflammatory breast cancer. Int J Clin Exp Med. 2011:4:265-75.
98. Hofmann UB, Westphal JR, Zendman AJ, et al. Expression and activation of matrix metalloproteinase-2 (MMP-2) and its co-localization with membranetype 1 matrix metalloproteinase (MT1-MMP) correlate with melanoma progression. J Pathol. 2000;191:245-56.

99. Nakamura $\mathrm{H}$, Ueno H, Yamashita $\mathrm{K}$, et al. Enhanced production and activation of progelatinase $\mathrm{A}$ mediated by membrane-type 1 matrix metalloproteinase in human papillary thyroid carcinomas. Cancer Res. 1999:59:467-73.

100. Jo Y, Yeon J, Kim HJ, et al. Analysis of tissue inhibitor of metalloproteinases2 effect on pro-matrix metalloproteinase-2 activation by membrane-type 1 matrix metalloproteinase using baculovirus/insect-cell expression system. Biochem J. 2000;345(Pt 3):511-9.

101. Lehti K, Lohi J, Valtanen $H$, et al. Proteolytic processing of membrane-type-1 matrix metalloproteinase is associated with gelatinase $\mathrm{A}$ activation at the cell surface. Biochem J. 1998:334(Pt 2):345-53.

102. Lu C, Li XY, Hu Y, et al. MT1-MMP controls human mesenchymal stem cell trafficking and differentiation. Blood. 2010;115:221-9.

103. Shi C, Jia T, Mendez-Ferrer S, et al. Bone marrow mesenchymal stem and progenitor cells induce monocyte emigration in response to circulating tolllike receptor ligands. Immunity. 2011;34:590-601.

104. Rafei M, Hsieh J, Fortier S, et al. Mesenchymal stromal cell-derived CCL2 suppresses plasma cell immunoglobulin production via STAT3 inactivation and PAX5 induction. Blood. 2008;112:4991-8.

105. Rafei M, Campeau PM, Aguilar-Mahecha A, et al. Mesenchymal stromal cells ameliorate experimental autoimmune encephalomyelitis by inhibiting CD4 Th17 T cells in a CC chemokine ligand 2-dependent manner. J Immunol. 2009;182:5994-6002.

106. Katayama Y, Battista M, Kao WM, et al. Signals from the sympathetic nervous system regulate hematopoietic stem cell egress from bone marrow. Cell. 2006;124:407-21.

107. Méndez-Ferrer S, Lucas D, Battista M, et al. Haematopoietic stem cell release is regulated by circadian oscillations. Nature. 2008;452:442-7.

108. Fadini GP, Albiero M, Vigili de Kreutzenberg S, et al. Diabetes impairs stem cell and proangiogenic cell mobilization in humans. Diabetes Care. 2013:36:943-9.

109. Ferraro F, Lymperi S, Méndez-Ferrer S, et al. Diabetes impairs hematopoietic stem cell mobilization by altering niche function. Sci Transl Med. 2011;3:104ra101.

110. DiPersio JF. Diabetic stem-cell "mobilopathy". N Engl J Med. 2011;365:2536-8.

111. Holmes D. Diabetes: SDF-1 dysregulation mediates diabetic stem cell mobilopathy. Nat Rev Endocrinol. 2015;11:318.

\section{Submit your next manuscript to BioMed Central and we will help you at every step:}

- We accept pre-submission inquiries

- Our selector tool helps you to find the most relevant journal

- We provide round the clock customer support

- Convenient online submission

- Thorough peer review

- Inclusion in PubMed and all major indexing services

- Maximum visibility for your research

Submit your manuscript at www.biomedcentral.com/submit
Biomed Central 